\title{
Preventive Maintenance Interval Prediction: a Spare Parts Inventory Cost and Lost Earning Based Model
}

\author{
O. A. Adebimpe \\ Dept of Industrial and Production \\ Engineering, \\ University of Ibadan, \\ Ibadan, Nigeria \\ sebolic@yahoo.com
}

\author{
V. O. Oladokun \\ Dept of Industrial and Production \\ Engineering, \\ University of Ibadan, \\ Ibadan, Nigeria \\ victordokun@yahoo.com
}

\author{
O. E. Charles-Owaba \\ Dept of Industrial and Production \\ Engineering, \\ University of Ibadan, \\ Ibadan, Nigeria \\ oecharlesowaba@yahoo.com
}

\begin{abstract}
In this paper, some preventive maintenance parameters in manufacturing firms were identified and used to develop cost based functions in terms of machine preventive maintenance. The proposed cost based model considers system's reliability, cost of keeping spare parts inventory and lost earnings in deriving optimal maintenance interval. A case of a manufacturing firm in Nigeria was observed and the data was used to evaluate the model.
\end{abstract}

Keywords-Preventive Maintenance; Maintenance Cost; Spare Parts Inventory.

\section{INTRODUCTION}

The term maintenance can be defined as all actions appropriate for retaining an item/part/equipment in, or restoring it to a satisfactory condition [1]. More specifically, maintenance includes the repair of broken equipment, the preservation of equipment conditions and the prevention of their failure, which ultimately reduces production losses and downtime and also reduces environmental and associated safety hazards. With the increasing pressure of high competition and stringent environmental and safety regulations, maintenance has shifted from being perceived as a "necessary evil" to being recognized as an effective tool for increased profitability. Maintenance has become an integrated part of the production process rather than a supporting or peripheral activity. Developing effective and optimum maintenance strategies and models has thus become a subject of research both in academic and in industry.

Preventive maintenance tends to inspect, adjust, replace, lubricates etc the machine components to avoid any likely failure. This involves the usage of consumables and spare parts. Some of the components that need replacement have to be replaced, the ones that need adjustment have to be adjusted properly etc in accordance with manufacturers' specification. In [2], a preventive maintenance system is indicated to consist of routine actions taken in a planned manner to prevent breakdowns and to ensure smooth operational accuracy. Industries carry out preventive maintenance (PM) on machinery and equipment to prevent or slow down deterioration. It is important to note that PM is justified only when it is cost effective, reduces the occurrences of failure and extends the useful life of the equipment. The spare parts involved in this activity need to be planned for and well managed to avoid shortages and also unnecessary tying down of capital. The question of how, when and what spare parts to be ordered becomes a challenge to be dealt with by the maintenance team. Failure to make proper planning on the spare parts inventory has led to disrupted or poor maintenance operations resulting in economic loss for many organizations.

Maintenance activities are increasingly becoming complex in view of the rapidly expanding product diversification and the challenge for improved efficiency of manufacturing systems. Hence, existing models have considered a lot of ways to predict the optimal preventive maintenance interval, but many have excluded some of the pertinent costs associated with maintenance activities. In order to reflect reality there is the need to capture cost components associated with the spare parts inventory and lost earnings during the preventive maintenance intervals. This study is aimed at determining the optimal preventive maintenance interval that minimizes the cost of spare parts inventory and sum of lost earnings during preventive maintenance activities as a result of loss of production.

Numerous researchers have demonstrated great efforts towards the study of the preventive maintenance models. An (s, S) PM policy in which the PM work-orders are performed as soon as inventory reaches a certain threshold value, $\mathrm{S}$ was described in [3]. PM and safety stock strategies were formulated assuming that the PM tasks are scheduled every $M$ units of time and derived $M$ by minimizing expected cost per unit time. A control policy where the system undergoes repair once it breaks down was described in [4]. The production resumes immediately after repair, continuing until the inventory level reaches a threshold value. A multi-criteria preventive maintenance optimization model to find the optimal preventive maintenance intervals of components in a production system was developed in [5]. An economic manufacturing quantity (EMQ) model was proposed in [6] and an improvement to a stochastic PM model to find an optimal 
policy, where manufacturing quantity and safety stock are derived minimizing the cost per unit time was described in [7]. The basic cost-based approach to maintenance planning that was developed by Jardine in 1973 was studied in [8] and was later extended in [9]. Machine reliability and preventive maintenance planning were considered for a cellular manufacturing system for an improved performance. A simulation model to find the best preventive maintenance strategy in semiconductor manufacturing plants was described in [10]. An analytical model for the joint determination of an optimal age-dependent buffer inventory and PM policy in a production environment that is subject to random machine breakdowns was formulated in [11]. The optimal preventive maintenance schedules by considering two modes of failure (maintainable and non-maintainable) and the number of PM tasks dependent on different failure rates of the system was investigated in [12]. A development of a combined opportunity cost and reliability model, taking into consideration a factor that was not considered in [8], was described in [13].

A computer-aided preventive maintenance program was developed in [14] in order to improve system availability and maintenance resources. The PM labor force requirement was, the availability of the equipment, reliability and total maintenance cost were modeled. Genetic algorithms were employed to find optimum solution for different maintenance planning and scheduling with multi-objective optimization research on multi parallel machine in [15] made. The reliability and time were the two main constraints and due to that, a lower bound for reliability was introduced. An optimal preventive maintenance model for steam turbines where Weibull distribution was applied to study the problems of a thermal power station was presented in [2] and it was shown that the total cost of replacement was decreasing as the cycle length was increasing. The model didn't consider how the components to be replaced are being ordered or the cost which is attached to it. The preventive maintenance strategy and minimal repair were incorporated into the production process in the traditional integrated inventory model in [16] but didn't take into consideration the inventory of the spare parts needed for the preventive maintenance activities itself rather, they tried to address the problem involved with the supply chain and production.

It should be noted that past works on models of preventive maintenance are yet to incorporate the cost of the spare parts inventory cost and the lost earnings during preventive maintenance. Consequently, this work develops a model to incorporate these using Weibull distribution.

\section{MODEL DEVELOPMENT}

In this section, the procedure for identifying preventive maintenance cost related parameters for a manufacturing firm is presented. Also, outlined are the preventive maintenance cost function development process and the definition and solution procedure to the preventive maintenance optimization problem. To identify preventive maintenance cost parameters, relevant literature was reviewed, some manufacturing firms in Nigeria were visited, relevant personnel interviewed, maintenance process observed and relevant records examined.

\section{A. Model Notations}

This model uses the cost based approach to minimize total maintenance cost that assures the desired level of machine reliability. The following notations of the model are defined:

1. $t p m$ is the preventive maintenance interval.

2. $T C$ is the total maintenance cost for a planning horizon...

3. $C_{o}$ is the fixed cost of carrying out a planned preventive maintenance (preparation cost).

4. $C_{p m}$ is the estimated average preventive maintenance cost per maintenance to return machine to the "as-goodas-new" condition.

5. $C_{f}$ is the breakdown maintenance cost during the interval tpm

6. $H(t p m)$ is the average number of machine failures during the interval tpm

7. $D_{m}$ is the estimated average duration for a breakdown maintenance.

8. $D_{t}$ is the estimated duration of time used for a preventive maintenance activities.

9. $\quad P_{l}$ is the estimated profit loss per hour by the company due to downtime.

10. $C_{o c}$ is the cost of placing an order for the materials that are used in carrying out preventive maintenance activities.

11. $C_{h c}$ is the holding cost of the materials used for preventive maintenance activity in a year.

12. $r$ is the demand of the preventive maintenance material per year.

13. $\alpha$ and $\beta$ are respectively the scale parameter and the shape parameter of the Weibull distribution for the machine in question.

14. $T$ is the total operating time of the machine in a planning horizon.

\section{B. Model Assumptions}

a. The failure of the machine is characterized by Weibull distribution (increasing rate of failure with age).

b. There is a fixed cost for carrying out preventive maintenance and it is deterministic

c. The cost of executing one breakdown repair is constant and deterministic.

d. The preventive maintenance spare parts are ordered in bulk and received in bulk

e. There is minimum acceptable reliability of the machine. 
f. The ordering cost and holding cost for the bulk preventive maintenance materials are deterministic.

g. The replenishment size of the preventive maintenance material is constant and replenishments are made whenever the inventory reaches the prescribed zero level.

h. Demand is deterministic at a constant rate of $r$.

i. The duration for preventive maintenance is deterministic.

j. The depreciation of the equipment is negligible since we assumed that the machine is as good as new each time they are maintained.

k. The labors used for the maintenance are the employees of the company so they are always available.

\section{The Cost Function Development}

Expanding on the cost function of [8], the cost component of this model can be summarized as follows: developing the total maintenance cost function for a planning horizon, where total maintenance cost is defined as the summation of all the costs involved in the maintenance made up of the following components.

Total maintenance $\cos t=\{$ Preparation cost of preventive maintenance + Cost of executing preventive maintenance + Cost of executing breakdown maintenance+Lost earnings during breakdown maintenance+Lost earnings during preventive maintenance $\}+$ Cost of Preventive Maintenance Materials Inventory Management

We now describe and develop mathematical expression for each cost component.

1. Preparation cost for the preventive maintenance activities $C_{o}$ : this is a fixed cost per preventive maintenance encompassing all cost for mobilizing resources, equipment into site, and cost of all preparatory paper works.

2. Cost of executing preventive maintenance $C_{p m}$ : This includes costs of tools materials and labour (include portion of employees' salary for the involvement in preventive maintenance)

3. Cost of executing breakdown maintenance $C_{b m}$ : This includes cost of materials, labour, tools used, for breakdown maintenance within an interval tpm expressed as $C_{b m}=C_{f}(t p m / \alpha)^{\beta}$

where, $C_{f}$ is the cost of breakdown maintenance per machine failure and $H(t p m)$ the average number of machine failures during a preventive maintenance interval.

Note: $H(t p m)=(t p m / \alpha)^{\beta}$

$C_{b m}=C_{f}(t p m / \alpha)^{\beta}$
4. Lost Earnings during Breakdown Maintenance $L E_{b m}$ : This accounts for earning opportunities forfeited during downtime due to sudden failure: $L E_{b m}=D_{m} P_{l}(t p m / \alpha)^{\beta}$

5. Lost Earnings during Preventive Maintenance $L E_{p m}$ : This accounts for earning opportunities forfeited during downtime associated with preventive maintenance activities:

$$
L E_{p m}=D_{t} P_{l}
$$

6. Cost of spare parts Inventory to support Preventive Maintenance tc: The inventory cost has two components, the holding cost and the ordering cost based on the economic order quantity inventory model.

That is, holding cost $C_{h c} q / 2$ and ordering costs $C_{o c} r / q$.

If $\operatorname{tc}(I)$ is the total cost of inventory per unit time then.

$$
t c(I)=C_{h c} q / 2+C_{o c} r / q
$$

Since $t=q / r$ which is the schedule period of ordering then,

$$
q=\operatorname{tr}
$$

From (1) and (2)

$$
\operatorname{tc}(I)=C_{h c} t r / 2+C_{o c} / t
$$

Since (3) is the unit cost per unit time, therefore the total unit cost over the planning horizon $\mathrm{T}$.

Then:

$$
T C(I)=T . t c=T C_{h c} t r / 2+T C_{o c} / t
$$

Note: $t$ is actually equivalent to $t p m+D_{t}$ for a preventive maintenance cycle

Hence:

$T C(I)=T . t c=T C_{h c}\left(t p m+D_{t}\right) r / 2+T C_{o c} /\left(t p m+D_{t}\right)$

Therefore:

$$
\begin{gathered}
T C(T)=C_{o}+C_{b m}+C_{p m}+L E_{p m}+L E_{b m}+T C(I) \\
\text { i.e } \begin{array}{c}
T C(T)=\left\{C_{o}+C_{p m}+C_{f}(t p m / \alpha)^{\beta}+D_{m} P_{l}(t p m / \alpha)^{\beta}\right. \\
\left.+D_{t} P_{l}\right\}+T C_{h c}\left(t p m+D_{t}\right) r / 2+T C_{o c} / t p m+D_{t}
\end{array}
\end{gathered}
$$

Therefore, a cost minimization problem can be defined based on the above cost function to determine the optimal values of the preventive maintenance decision variables as follows. 
Min

$$
\begin{aligned}
& T C(T)=\left\{\frac{T}{D_{t}+t p m} C_{o}+\frac{T}{D_{t}+t p m} C_{p m}+\frac{T}{D_{t}+t p m} C_{f}(t p m / \alpha)^{\beta}\right. \\
& +\frac{T}{D_{t}+t p m} D_{m} P_{l}(t p m / \alpha)^{\beta}+\frac{T}{D_{t}+t p m} D_{t} P_{l}+T C_{h c}\left(t p m / D_{t}\right) r / 2 \\
& \left.+\frac{T}{D_{t}+t p m} C_{o c}\right\}
\end{aligned}
$$

Subject to

$$
\begin{aligned}
& \text { tpm } \leq \alpha\left\{\operatorname{In}(1 / R(\text { tpm }))^{1 / \beta}\right. \\
& R(t p m) \leq \text { UpperBound }
\end{aligned}
$$

Where

$$
\frac{T}{D_{t}+t p m}
$$

The model when solved computes the optimum cost and PM interval combination using the objective function (i.e., the total cost TC (T)), the reliability of the machine and the determined values of $\alpha$ and $\beta$. The procedure can be repeated for various values of reliability. A series of preventive maintenance intervals and total cost combinations corresponding to different reliability probabilities will be generated to provide a basis for choosing the appropriate maintenance interval that will best suit the needs of the organization depending on the reliability level desired for the concerned machine.

\section{Solution Procedure}

Step 1. Specify the values of the parameters $C_{o}, C_{p m}$, $C_{f}, D_{t}, P_{l}, C_{h c}, r$, Coc , UpperBound,$\alpha$ and $\beta$

Step 2: Compute the optimum tpm using the reliability function of the model developed in (7)

Step 3: Substitute the tpm in the cost objective equation to compute the total cost $T C$ in the model at a minimum reliability and the preventive interval tpm computed.

Step 4: Repeat this for a range of reliability and check for the minimum cost.

\section{APPLICATION, RESULTS AND DISCUSSION}

The manufacturing firm under study is a cash crop processing company in South-West of Nigeria. This company is one of the famous beverages company in Nigeria whose products are widely consumed on daily basis across the country and in the neighbouring countries as well. Because of the high demand and competitive market in which the firm is involved, there is need for a fact based determination of a realistic planned preventive maintenance interval to avoid downtime experienced as a result of frequent failures, particularly of the critical machine under consideration. The reliability of this machine is of importance as its failure could cause a serious production problem. We shall now apply the firm's internal data to the developed model to test its validity and realism, and in the process establish an optimal preventive maintenance interval for the critical machine under study. We begin by establishing values of the Weibull distribution parameters $\alpha$ and $\beta$ and other parameters as specified in the solution procedure. The data used are shown in Table I.

TABLE I. MANUFACTURING FIRM DATA USED

\begin{tabular}{|c|c|c|}
\hline Item No. & Parameters & Values \\
\hline 1 & MTBF (hours) & 187 \\
\hline 2 & $\boldsymbol{\beta}$ & 1.21 \\
\hline 3 & $\alpha$ & 199.61 \\
\hline 4 & $\mathrm{C}_{\mathrm{o}}$ (Naira) & 2560 \\
\hline 5 & $\mathrm{C}_{\mathrm{pm}}$ (Naira) & 15190 \\
\hline 6 & $\mathrm{C}_{\mathrm{f}}$ (Naira) & 4500 \\
\hline 7 & (Naira) & 2.5 \\
\hline 8 & $\mathrm{D}_{\mathrm{m}}$ (hours) & $8760(1$ year) \\
\hline 9 & $\mathrm{~T}_{\text {(hours })}$ & 1650 \\
\hline 10 & $\mathrm{D}_{t}$ (Hours) & 250 \\
\hline 11 & $C_{o c}$ (Naira) per order & 700 \\
\hline 12 & $C_{h c}$ (Naira)per quantity & \\
\hline 13 & $\boldsymbol{r}$ & \\
\hline
\end{tabular}

\section{DISCUSSION OF RESULTS}

The results of the model are as shown in Table II and Figures 1 and 2. This work first considered the inclusion of the spare parts inventory cost which is shown in Table II. The results in Table II show that there is a minimum point at the Total Maintenance Cost (TC) at which the preventive maintenance could take place. This minimum point for the total maintenance cost at 100 percent inventory cost consideration (i.e $\mathrm{I}=1$ ) is $1,349,105$ Naira at tpm 173.58 for a planning horizon shown in Figure 1 for different percentage of inventory cost. Table II shows that at the 40 percent and 50 percent consideration of inventory cost the tpm are the same though with different Total Maintenance Costs. Also, for 70 percent and 80 percent inventory. This implies that there could be a uniform preventive maintenance interval tpm for the machines in a production line even when they have different cost implication, so far the minimum total maintenance cost is considered.

Considering the lost earning due to preventive maintenance, the results are shown in Table III and described in Figure 2. As shown, there is an inverse relationship between the preventive maintenance interval tpm and the Total Maintenance Cost (TC). Considering the lost earnings due to preventive maintenance, the Total Maintenance Cost (TC) decreases continually with an increase in the preventive maintenance interval tpm and consequently reducing the reliability of the machine without giving a concise answer of when the maintenance could be done should the cost be given a priority. This suggests that the preventive maintenance interval should not be attached to the money that could be probably lost during the period of maintenance as this could lead to more catastrophic failures if the lost is prioritized. 


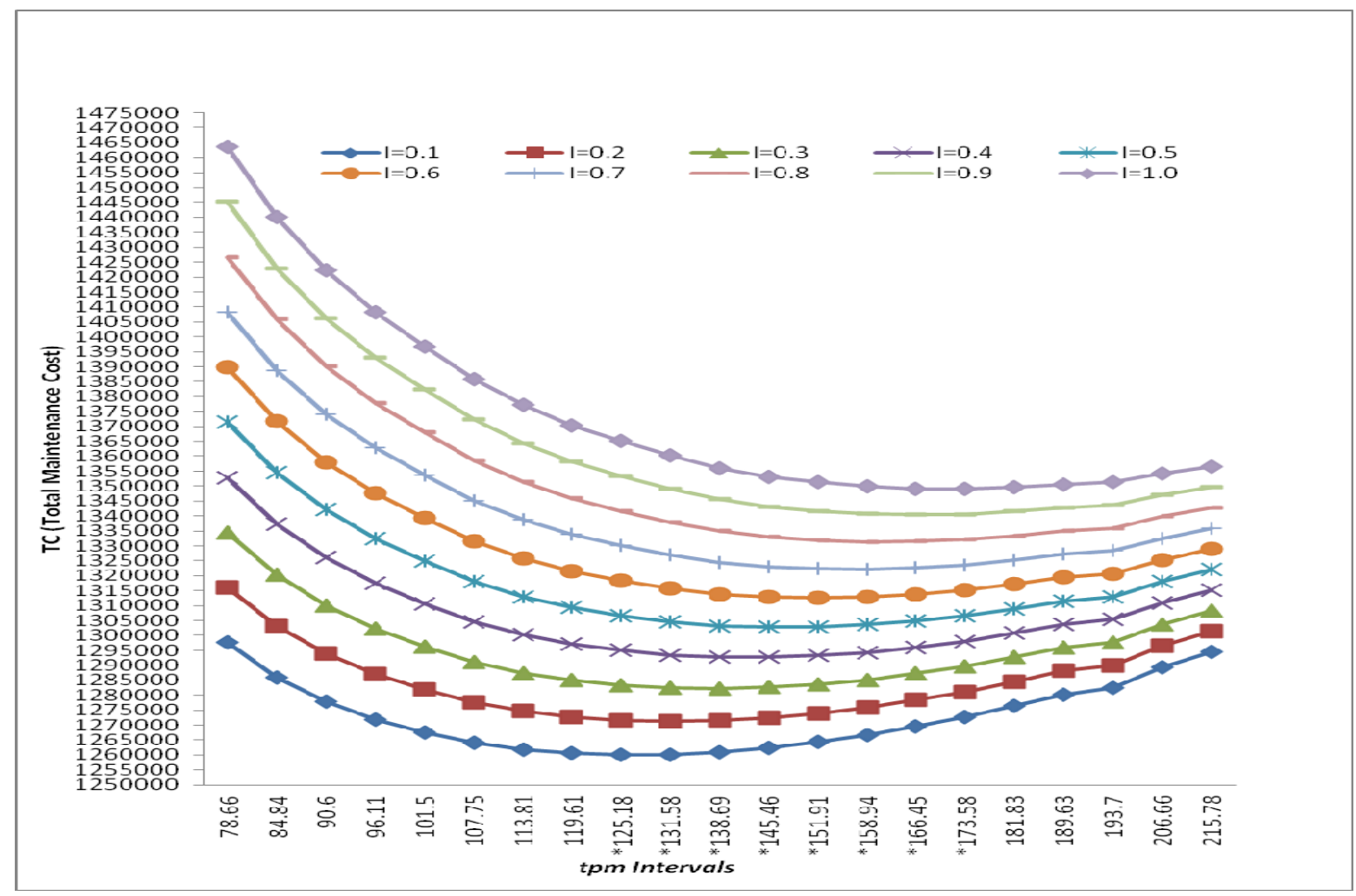

Fig. 1. Graph showing the relationship between the Total Maintenance Cost and Preventive Maintenance Interval of a Manufacturing Firm with Spare Parts Inventory Cost Consideration at different Percentage (i.e. $\mathrm{I}=0.1$ to 1 )

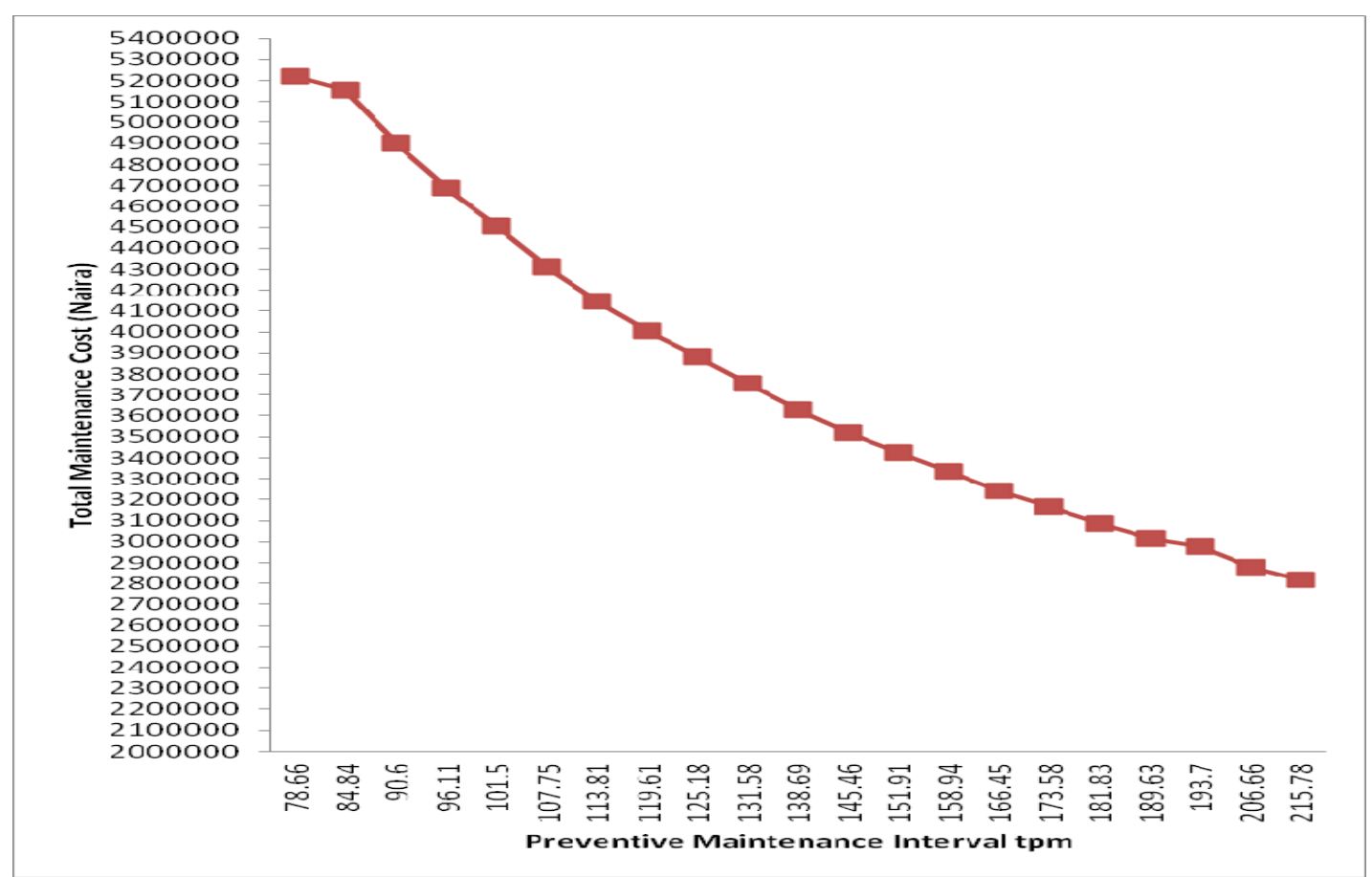

Fig. 2. Graph showing the relationship between the Total Maintenance Cost and Preventive Maintenance Interval of a Manufacturing Firm with Lost Earning at 100 percent Spare Parts Inventory Cost Consideration (i.e. $\mathrm{I}=1$ ) 
TABLE II. RESULTS OF TPM AND TOTAL COST OF MAINTENANCE OF A MANUFACTURING FIRM.

\begin{tabular}{|c|c|c|c|c|c|c|c|c|c|c|}
\hline \multirow{2}{*}{$\begin{array}{c}\text { Min } \\
\text { R }\end{array}$} & \multirow{2}{*}{$\begin{array}{c}\text { PM } \\
\text { Interval } \\
\text { tpm }\end{array}$} & \multicolumn{9}{|c|}{ Total Cost of Maintenance (Naira) at } \\
\hline & & $\mathrm{I}=\mathbf{0 . 1}$ & $\mathrm{I}=\mathbf{0 . 2}$ & $\mathrm{I}=\mathbf{0 . 3}$ & $\mathrm{I}=\mathbf{0 . 4}$ & $\mathrm{I}=0.5$ & $\mathrm{I}=0.6$ & $\mathrm{I}=\mathbf{0 . 7}$ & $\mathrm{I}=\mathbf{0 . 8}$ & $\mathrm{I}=0.9$ \\
\hline 0.75 & 78.66 & 1297552 & 1316005 & 1334459 & 1352913 & 1371367 & 1389821 & 1408275 & 1426729 & 1445182 \\
\hline$\overline{0.73}$ & 84.84 & 1286017 & 1303139 & 1320260 & 1337382 & 1354503 & 1371625 & 1388746 & 1405868 & 1422989 \\
\hline 0.71 & 90.6 & 1277878 & 1293923 & 1309967 & 1326011 & 1342055 & 1358099 & 1374143 & 1390187 & 1406232 \\
\hline 0.69 & 96.11 & 1271966 & 1287101 & 1302236 & 1317371 & 1332506 & 1347641 & 1362776 & 1377911 & 1393046 \\
\hline$\overline{0.67}$ & 101.5 & 1267620 & 1281962 & 1296304 & 1310646 & 1324987 & 1339329 & 1353671 & 1368013 & 1382355 \\
\hline 0.65 & 107.75 & 1264032 & 1277554 & 1291076 & 1304598 & 1318120 & 1331642 & 1345164 & 1358686 & 1372208 \\
\hline$\overline{0.63}$ & 113.81 & 1261768 & 1274582 & 1287396 & 1300210 & 1313024 & 1325837 & 1338651 & 1351465 & 1364279 \\
\hline 0.61 & 119.61 & 1260519 & 1272723 & 1284927 & 1297130 & 1309334 & 1321538 & 1333742 & 1345945 & 1358149 \\
\hline 0.59 & $* 125.18$ & 1260021 & 1271692 & 1283364 & 1295036 & 1306707 & 1318379 & 1330051 & 1341722 & 1353394 \\
\hline 0.57 & *131.58 & 1260155 & 1271271 & 1282388 & 1293504 & 1304620 & 1315737 & 1326853 & 1337970 & 1349086 \\
\hline 0.55 & *138.69 & 1261036 & 1271597 & 1282157 & 1292717 & 1303278 & 1313838 & 1324398 & 1334959 & 1345519 \\
\hline 0.53 & $* 145.46$ & 1262463 & 1272545 & 1282627 & 1292709 & 1302791 & 1312874 & 1322956 & 1333038 & 1343120 \\
\hline 0.51 & $* 151.91$ & 1264262 & 1273929 & 1283595 & 1293262 & 1302929 & 1312595 & 1322262 & 1331928 & 1341595 \\
\hline 0.49 & *158.94 & 1266627 & 1275880 & 1285133 & 1294385 & 1303638 & 1312891 & 1322144 & 1331396 & 1340649 \\
\hline 0.47 & $* 166.45$ & 1269537 & 1278387 & 1287237 & 1296087 & 1304937 & 1313787 & 1322637 & 1331487 & 1340337 \\
\hline 0.45 & $* 173.58$ & 1272601 & 1281102 & 1289602 & 1298102 & 1306603 & 1315103 & 1323603 & 1332104 & 1340604 \\
\hline 0.43 & 181.83 & 1276444 & 1284574 & 1292705 & 1300836 & 1308967 & 1317098 & 1325229 & 1333359 & 1341490 \\
\hline 0.41 & 189.63 & 1280314 & 1288126 & 1295937 & 1303749 & 1311561 & 1319372 & 1327184 & 1334996 & 1342807 \\
\hline 0.39 & 193.7 & 1282410 & 1290065 & 1297721 & 1305376 & 1313032 & 1320687 & 1328343 & 1335999 & 1343654 \\
\hline 0.37 & 206.66 & 1289359 & 1296559 & 1303760 & 1310961 & 1318161 & 1325362 & 1332562 & 1339763 & 1346963 \\
\hline 0.35 & 215.78 & 1294445 & 1301359 & 1308273 & 1315187 & 1322101 & 1329015 & 1335929 & 1342843 & 1349757 \\
\hline
\end{tabular}

TABLE III. RESULTS TPM AND TOTAL COST OF MAINTENANCE OF A MANUFACTURING FIRM WITH INVENTORY CONSIDERATION AND LOST EARNING.

\begin{tabular}{|c|c|c|c|c|c|c|c|c|}
\hline $\begin{array}{c}\text { Min } \\
\mathbf{R}\end{array}$ & $\begin{array}{c}\text { PM } \\
\text { Interval } \\
\text { tpm }\end{array}$ & $\begin{array}{c}\text { Total Cost } \\
\text { (Naira) }\end{array}$ & $\begin{array}{c}\text { Min } \\
\mathbf{R}\end{array}$ & $\begin{array}{c}\text { PM } \\
\text { Interval } \\
\text { tpm }\end{array}$ & $\begin{array}{c}\text { Total Cost } \\
\text { (Naira) }\end{array}$ & $\begin{array}{c}\text { Min } \\
\mathbf{R}\end{array}$ & $\begin{array}{c}\text { PM } \\
\text { Interval } \\
\text { tpm }\end{array}$ & $\begin{array}{c}\text { Total Cost } \\
\text { (Naira) }\end{array}$ \\
\hline & & $\mathbf{I = 1 . 0}$ & & & & & & \\
\hline 0.75 & 78.66 & 5220784 & 0.61 & 119.61 & 4006922 & 0.47 & $* 166.45$ & 3243810 \\
\hline 0.73 & 84.84 & 5157225 & 0.59 & $* 125.18$ & 3884318 & 0.45 & $* 173.58$ & 3165904 \\
\hline 0.71 & 90.6 & 4903070 & 0.57 & $* 131.58$ & 3756919 & 0.43 & 181.83 & 3083988 \\
\hline 0.69 & 96.11 & 4689421 & 0.55 & $* 138.69$ & 3629927 & 0.41 & 189.63 & 3013647 \\
\hline 0.67 & 101.5 & 4503691 & 0.53 & $* 145.46$ & 3521220 & 0.39 & 193.7 & 2979394 \\
\hline 0.65 & 107.75 & 4312505 & 0.51 & $* 151.91$ & 3427228 & 0.37 & 206.66 & 2880148 \\
\hline 0.63 & 113.81 & 4148027 & 0.49 & $* 158.94$ & 3334047 & 0.35 & 215.78 & 2818160 \\
\hline
\end{tabular}

\section{SUMMARY AND CONCLUSION}

The maintenance records of an existing manufacturing firm reveals that a structured way of determining the preventive maintenance interval will help manufacturing companies to appropriate maximum benefits from application of preventive maintenance policy. The identification of parameters helped improve the existing model and will enhance the practitioners' idea in capturing the comprehensive costs that are involved in the preventive maintenance activities of the firm. The developed model is suitable for predicting an optimal preventive maintenance interval in a profit oriented manufacturing or service organization, where emphasis is laid on carrying out the preventive maintenance activities at a minimum cost. The model is able to predict an optimum interval for preventive maintenance at a minimum cost for the company and can be used as a decision support system. Also it can help determining the actual maintenance cost for each machine and thus evaluate the excesses of the company's maintenance team.

\section{REFERENCES}

[1] B. S. Dhillon, Engineering Maintenance: A Modern Approach , CRC Press. Boca Raton FL, 2002

[2] M. G. Sobamowo, S. O. Ismail, S. J. Ojolo, A. A. Adebayo, "Optimal preventive maintenance models for steam turbines: a case study of egbin thermal station, Lagos, Nigeria", International Journal of Mechanical Computational and Manufacturing Research, Vol. I, No. 1, pp 6-11, 2012

[3] M. M. Srinivasan, H. S. Lee, "Production-inventory systems with preventive maintenance", IIE Transactions, Vol. 28, No. 11, pp. 879$890,1996$.

[4] R. D. Meller, D. S. Kim, "The impact of preventive maintenance on system cost and buffer size", European Journal of Operational Research Vol. 95, No. 3, pp. 577-591, 1996

[5] C. Chareonsuk, N. Nagarur, M. T. Tabucanon, A multicriteria approach to the selection of preventive maintenance intervals, International Journal of Production Economics, Vol. 49, No. 1, pp. 55-64, 1997

[6] K. L. Cheung, W. H. Hausman, "Joint determination of preventive maintenance and safety stocks in an unreliable production environment", Naval Research Logistics Vol. 44, No. 3, pp. 257-272, 1997 
[7] T. Dohi, H. Okamura, S. Osaki, "Optimal control of preventive maintenance schedule and safety stocks in an unreliable manufacturing environment", International Journal of Production Economics Vol. 74, No. 1-3, pp. 147-155, 2001

[8] K. Das, R. S. Lashkari, S. Sengupta, "Machine reliability and preventive maintenance planning for cellular manufacturing systems", European Journal of Operations Research Vol. 183, No. 1, pp. 162-180, 2007

[9] M. S. Talukder, G. M. Knapp, "Equipment assignment to multiple overhaul blocks in series system", Journal of Quality in Maintenance Engineering, Vol. 8, No. 4, pp.319-330, 2002

[10] A. Crespo Márquez, The Maintenance management framework: models and methods for complex systems maintenance, Springer Series in Reliability Engineering. Springer-Verlag. Berlin, 2007

[11] J. P. Kenne, A. Gharbi, M. Bei, "Age-dependent production planning and maintenance strategies in unreliable manufacturing systems with lost sale", European Journal of Operational Research, Vol. 178, No. 2, pp. 408-420, 2007

[12] I. T. Castro, "A model of imperfect preventive maintenance with dependent failure modes", European Journal of Operational Research Vol. 196, No. 1, pp. 217-224, 2009

[13] G. V. Ojeih, Development of a combined opportunity cost and reliability model for preventive maintenance interval determination, MSc project, unpublished, 2012

[14] S. Afefy, "Maintenance Planning Based on Computer-Aided Preventive Maintenance Policy", International Multi conference of Engineers and Computer Scientists (IMECS), Hong Kong, March 14-16, 2012

[15] S. N. Mirabedini, H. Mina, S. H. Iranmanesh, "Multi-objective optimization research on multi parallel machine with different preventive maintenance planning and scheduling with genetic algorithm", International Journal of Academic Research in Business and Social Sciences, Vol. 2, No. 12, 2012

[16] F. Y. Ming, M. S. Chien, C. L. Ming, H. L. Hsu, C. T. Wei, "Integrated inventory model with decreasing probability of imperfect maintenance in a supply chain", International Multi conference of Engineers and Computer Scientists (IMECS), Hong Kong, March 13-15, 2013 